\title{
Concurrent End-Stage Cardiomyopathy and Aortic Disease in Patients with Marfan Syndrome: A Case Report and Literature Review
}

\author{
Timothy Smith ${ }^{1}$, Jose Sleiman ${ }^{1}$, Nikita Zadneulitca ${ }^{1}$, Cedric Sheffield ${ }^{1}$, Viviana Navas ${ }^{1}$, \\ Jaime Hernandez-Montfort ${ }^{1}$, Mauricio Velez ${ }^{1}$, and Nicolas Brozzi ${ }^{2}$ \\ ${ }^{1}$ Cleveland Clinic Florida \\ ${ }^{2}$ Cleveland Clinic Foundation
}

June 2, 2021

\begin{abstract}
Abstract Background: Marfan syndrome (MFS) is a connective tissue disorder that can lead to aortic disease, arrhythmias and heart failure. Many centers are reluctant to offer orthotopic heart transplantation (OHT) for patients with MFS with concurrent aortic disease due to complexity of the surgery and perceived inferior results when compared to patients without MFS. Methods: We present a case of a patient with MFS with previous Bentall procedure who underwent successful OHT, accompanied by a literature review on OHT performed for patients with MFS. Results and Conclusions: Patients with MFS who underwent OHT had no difference in mortality compared to patients without MFS. Even though OHT is technically more challenging when combined with concurrent intervention for aortic disease, it should be considered as a life-saving operation for patients with MFS.
\end{abstract}

\section{Hosted file}

MFS Case Report Final_Brozzi edits.docx available at https://authorea.com/users/417639/ articles/524655-concurrent-end-stage-cardiomyopathy-and-aortic-disease-in-patients-withmarfan-syndrome-a-case-report-and-literature-review 